\title{
Fast Approach for Clarification of Chromosomal Aberrations by Using LM-PCR and FT-CGH in Leukaemic Sample
}

\author{
Kathleen Dittmann ${ }^{a}$ Grzegorz Krzysztof Przybylski ${ }^{a, c}$ Piotr Grabarczyk ${ }^{a}$ \\ Gottfried Dölken $^{a}$ Stefan Gesk ${ }^{b}$ Reiner Siebert ${ }^{b}$ Christian Andreas Schmidt ${ }^{a}$ \\ ${ }^{a}$ Institute of Hematology/Oncology, University of Greifswald, Greifswald, and ${ }^{b}$ Institute of Human Genetics, \\ Christian Albrechts University of Kiel and University Hospital Schleswig-Holstein, Kiel, Germany; ' Institute of \\ Human Genetics, Polish Academy of Sciences, Poznan, Poland
}

\section{Key Words}

Chromosomal aberrations - Fine tiling comparative genomic hybridization - Ligation-mediated PCR •

Lymphoblastic leukaemia

\begin{abstract}
Chromosomal abnormalities, like deletions, amplifications, inversions or translocations, are recurrent features in haematological malignancies. However, the precise molecular breakpoints are frequently not determined. Here we describe a rapid analysis of genetic imbalances combining fine tiling comparative genomic hybridization (FT-CGH) and ligation-mediated PCR (LM-PCR). We clarified an inv(14)(q11q32) in a case of $T$ cell acute lymphoblastic leukaemia with a breakpoint in the TRA/D in $68 \%$ of cells detected by fluorescence in situ hybridization. FT-CGH showed several monoand biallelic losses within TRA/D. LM-PCR disclosed a TRA/D rearrangement on one allele. The other allele revealed an $\operatorname{inv}(14)(q 11 q 32)$, joining TRDD2 at 21,977,000 of $14 q 11$ together with the IGH locus at 105,948,000 and 3'-sequence of TRAC at 22,092,000 joined together with IGHV4-61 at 106,166,000.
\end{abstract}

This sensitive approach can unravel complex chromosomal abnormalities in patient samples with a limited amount of aberrant cells and may lead to better diagnostic and therapeutic options.

Copyright $\odot 2011$ S. Karger AG, Basel

\section{Introduction}

Chromosomal aberrations play a key role in malignant transformation and are frequently found in cancer cells using cytogenetic approaches. These chromosomal changes may lead to alteration of gene function and thereby presumably play a key role in malignant transformation [1]. So far, only few of these aberrations have been characterized at the molecular level, particularly in solid tumours. Many of these genomic alterations like inversions or translocations are accompanied by some loss or gain of genetic material. The combination of fine tiling comparative genomic hybridization (FT-CGH) and ligation-mediated PCR (LM-PCR) allows the molecular characterization of such alterations. FT-CGH detects ge- 
nomic imbalances like deletions or amplifications and LM-PCR enables the precise molecular characterization of the molecular breakpoints. Using these techniques we characterized selected genomic areas, including the loci of the T cell receptor $\alpha / \delta(T R A / D)$ and immunoglobulin heavy chain (IGH), and were able to clarify an inv(14) (q11q32) in a $\mathrm{T}$ cell acute lymphoblastic leukaemia (TALL) sample. This sensitive approach allows the clarification of even complex chromosomal abnormalities and can unravel involved genes. This knowledge may lead to a better understanding of pathogenetic aspects and may open new diagnostic and therapeutic options.

\section{Material and Methods}

Fine Tiling Comparative Genomic Hybridization

Aberrant genomic areas play a more and more important role in the clarification of alteration gene expressions. Since chromosomal translocations involving the TRA/D locus are usually accompanied by DNA losses due to $\mathrm{V}(\mathrm{D}) \mathrm{J}$ recombinations [1], we assumed that using FT-CGH and LM-PCR allows the detection of unknown translocation partners. For this analysis we used genomic DNA of a male patient (24 years of age) with a diagnosis of a mature T-ALL. Immunophenotyping of the peripheral blood cells revealed $49 \%$ of blast cells, which were positive for CD5, CD7, cyCD3, sCD3, CD8, TdT, CD52, TCRg/d. Chromosome R-banding analysis of the tumor cells at initial diagnosis revealed the karyotype: 46,t(X;5)(q26;q33),Y,del(1)(p3?4p3?5),add(11)(q13), $\operatorname{der}(12) \mathrm{t}(12 ; 18)(\mathrm{p} 13 ; \mathrm{q} 12) \operatorname{add}(12)(\mathrm{q} 21), \operatorname{inv}(14)(\mathrm{q} 11 \mathrm{q} 32), \operatorname{add}(17)(\mathrm{p} 11)$ [cp18]/46,XY. The patient was treated according to the ALL protocol, but died 8 weeks after diagnosis. In this study, the loci of $T R A / D$ and $I G H$ were analyzed by a custom-designed high-resolution fine-tiling oligonucleotid array of 385,000 oligonucleotids with a length of $45-60$ bp by using maskless array synthesizer technology (NimbleGen Systems, Reykjavik, Iceland). In brief: $3 \mu \mathrm{g}$ of genomic DNA of T-ALL sample and a human embryonic kidney cell line (HEK-293-T) (as control) were separately labelled with cyanine- 3 and cyanine- 5 dye. Both DNA samples were hybridized to a custom-designed FT-CGH array. The analysis of TRA/D on $14 q 11.2(21,130,000-22,130,000$; genomic build hg18, March 2006) with 19,500 probes and the IGH locus on $14 \mathrm{q} 32$ (105,080,586-106,360,585; genomic build hg18, March 2006) with 17,000 probes allowed the detection of genetic imbalances in these areas by comparing the signal intensity of the test and control DNA amount. The high probe density allows the statistic coverage of the genome with a hybridization probe of all 400 nucleotides.

\section{LM-PCR and Sequencing}

After detection of gains or losses of genetic material upon FTCGH, LM-PCR was performed to precisely determine the putative breakpoint region. In brief, $1 \mu \mathrm{g}$ of high-molecular-weight DNA was digested with blunt end restriction enzymes (EcoRV, DraI, PvuII, StuI, SmaI and HindII) and $50 \mu \mathrm{M}$ of an adaptor was ligated to both ends of the restriction fragments. The adaptor was prepared by hybridization of two oligonucleotides: sense: 5'-GTA ATA CGA CTC ACT ATA GGG CAC GCG TGG TCG ACG GCC

Clarification of Chromosomal

Aberrations Using LM-PCR and FT-CGH
CGG GCT GGT and reverse: $5^{\prime}$-ACC AGC CC-NH $\mathrm{N}_{2}$. The amine group blocks the extension of the $3^{\prime}$-end of the reverse oligonucleotide, thereby preventing formation of a primer-binding site on non-specific adaptor-ligated restriction fragments and adaptor duplexes. The ligation products were subjected to two rounds of PCR with nested adaptor-specific primers and two sets of TRA/Dspecific primers. The specific primers were located at the borders of the deleted regions. After gel electrophoresis PCR bands differing in size from the germline configuration observed in HEK 293$\mathrm{T}$ were excised from the gel, purified and directly sequenced. Sequence analyses of the regions of interest were performed via the University of California Santa Cruz Genome Bioinformatics database using BLAT.

\section{Results}

Here, we describe the precise molecular characterization of a T-ALL case with a split of the TRA/D found by fluorescence in situ hybridization (FISH) suggesting an $\operatorname{inv}(14)(q 11 \mathrm{q} 32)$. About $68 \%$ of cells of this sample showed a breakpoint affecting the TRA/D locus detectable by recently described TRA/D FISH probes RPCl11-242H9, RPCl11-447G18 and RPCl11-678M7 [2]. FT-CGH of the $T R A / D$ locus was performed in order to precisely clarify the chromosomal aberration. Several mono- and biallelic deletions (fig. 1a) were identified between positions 21,635,000, 21,976,000, 21,989,000 and 22,093,000 within the TRA/D locus. The SignalMap image revealed a complete loss of genetic material of the T-ALL sample on $14 q 11.2$ between $21,978,000$ and 21,989,000. By using two round LM-PCR in the region of 21,635,000 with two sets of nested forward primers V $\delta 1$-for(-275) and V81-for(-69) (5'-ACT CAA GCC CAG TCA TCA GT and 5'-CGT CGC CTT AAC CAT TTC AG, respectively), we clarified a normal rearrangement between TRDV1 and TRDJ1 (online suppl. fig. $2 \mathrm{~A}$, for all online suppl. materials, see www. karger.com/doi/10.1159/000330519) on one allele. This breakpoint of TRDJ1 at position $21,989 \mathrm{~K}$ was also visible in the FT-CGH. This rearrangement was confirmed by PCR with the gene specific primers V $\delta 1-f o r(-69)$ and Jס1(-189) on undigested genomic DNA (online suppl. fig. 2B). To clarify the remaining breakpoint in the area at $21,976,000$ two sets of nested forward gene specific primers D $\delta 2$-for(-73) and D $\delta 2$-for(-41) were used (5'-GGC AGC GGG TGG TGA TGG CAA AGT G and 5'-AGA GGG TTT TTA TAC TGA TGT, respectively). Sequencing of atypical fragments of this LM-PCR revealed the inversion of chromosome 14 with the breakpoints at sequence $21,977,838$ of 14 q11 together with the sequence of $105,948,661$ of $14 \mathrm{q} 32$ in the IGH locus (online suppl. fig. 3A). The joining region consisted of two fused recom- 

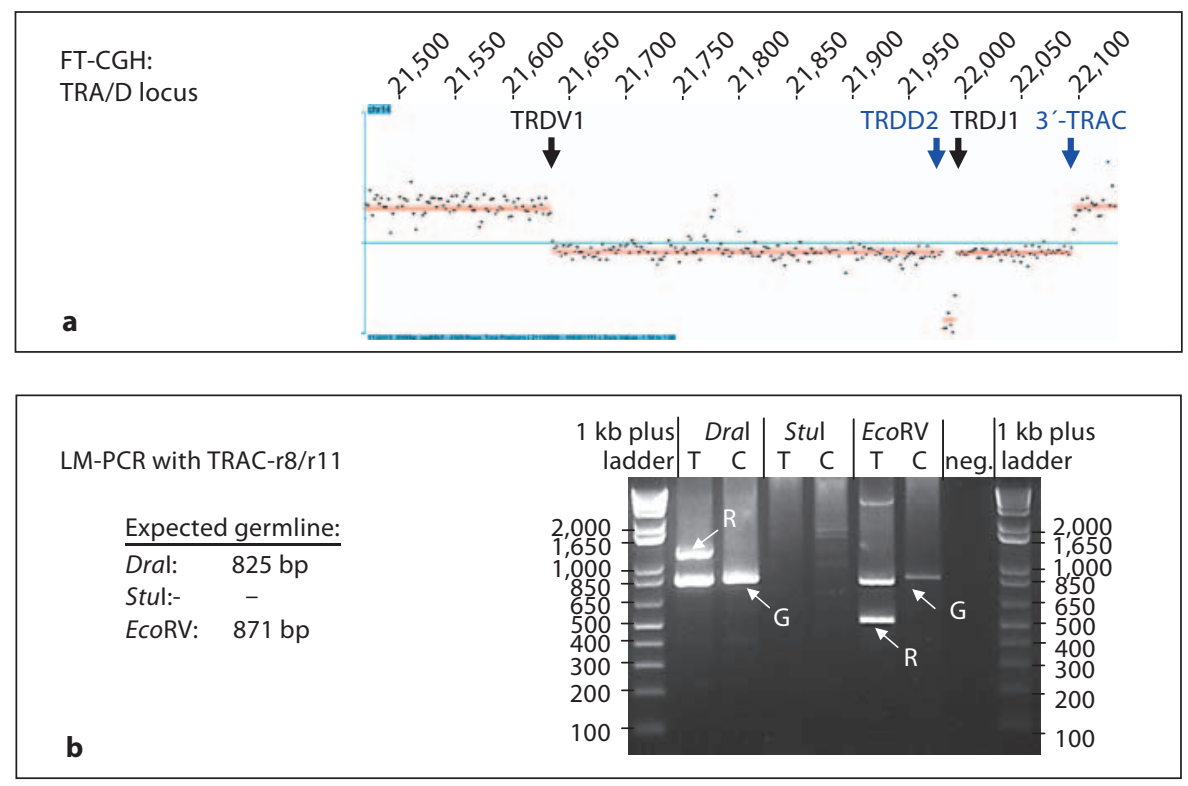

Fig. 1. a FT-CGH: TRA/D locus. FT-CGH analysis of the TRA/D locus on chromosome $14 \mathrm{q} 11$ revealed a large monoallelic deletion of 458,000 and located within it a small biallelic deletion of 11,000 . The chromosomal localization (in $\mathrm{kb}$ ) and the involved gene segments are indicated. Breakpoints of TRD rearrangement are indicating by black arrows. TRA/D breakpoints of inv(14)(q11q32) are shown by blue arrows. b LM-PCR with TRAC-r8/r11 LM-PCR with DraI, EcoRV and StuI restriction enzymes. $\mathrm{G}=$ Germline amplification products; $\mathrm{R}=$ rearranged fragments; T = T-ALL sample; $\mathrm{C}=$ HEK 293-T cell line used as a germline control. c Result: inv(14)(q11q32). Sequence analysis of the atypical rearrangement leading to the $\operatorname{inv}(14)(q 11 \mathrm{q} 32)$. By this inversion IGHV461 is agminate to a sequence locating the $3^{\prime}$-end of the constant region of TRA/D.

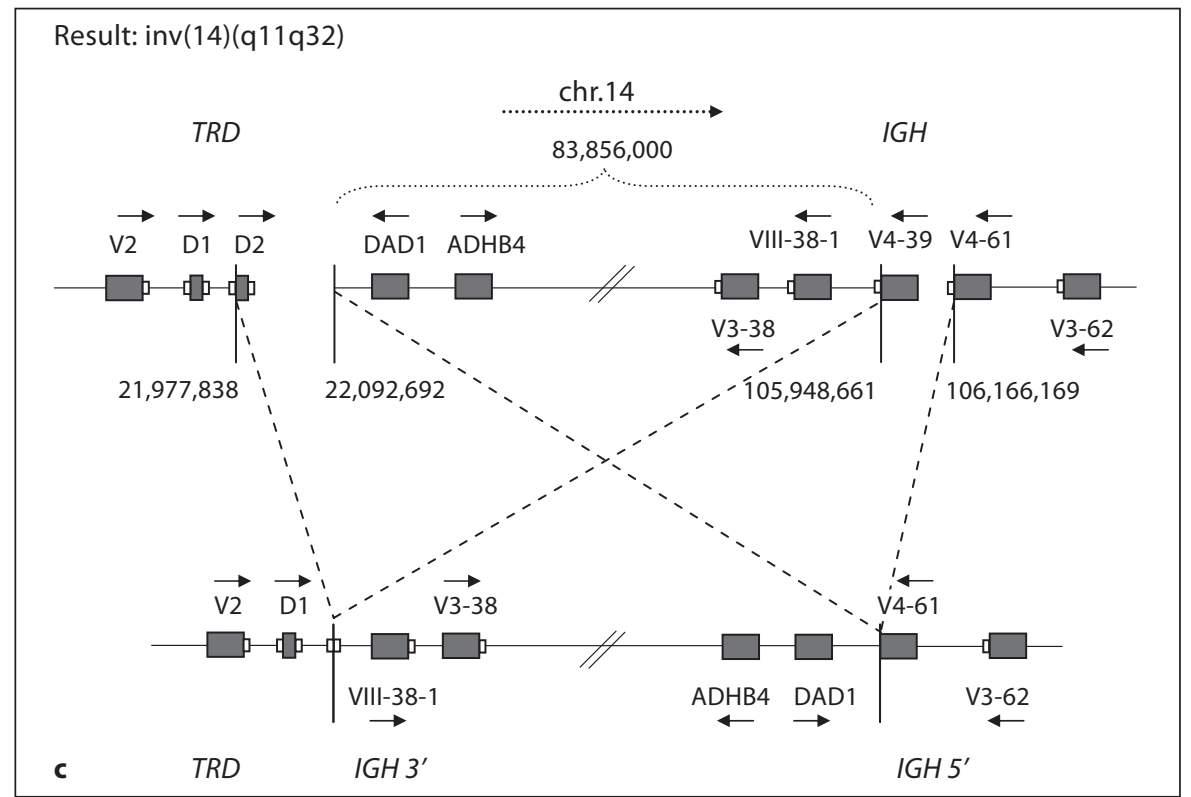

bination signal sequences, indicating a signal joint typical for a VDJ recombinase-mediated rearrangement. This rearrangement was confirmed again using gene-specific primers IGHV4-39-f1 (5'-AAA TGA GGT ATA ATG GGC TGT GCA GGT AC) and D $\delta 2(-73)$ on undigested DNA (online suppl. fig. 3B). Analysis of the breakpoint, located downstream of the TRA/D locus at position of 22,093,000 by LM-PCR (fig. 1b) with reverse gene-specific primers TRAC-r8/r11 (5'-CAC AAG GCC GTT CTA ATT CCC TCT GAC ATA and 5'-CTC TGA GGT TCT TGG AGG GGT CTG TCT T, respectively) revealed an inversion of $14 \mathrm{q} 11$ at position 22,092,696 joined together with IGHV4-61 at 106,166,169 of 14q32.33 (online suppl. fig. 4A). Here, the coding segment IGHV4-61 was fused to an intron sequence without a recombination signal sequence. This rearrangement was confirmed by regular PCR using genomic DNA with primer TRAC-rll and IGHV4-61-rl (online suppl. fig. 4B). This inversion inv(14) (q11q32) deleted genomic regions of 114,858 bp within the TRA/Dlocus and 217,508 bp of the IGH locus $(105,948,661-$ $106,166,169$ ) (fig. 1c). The deletion within the IGH locus was visible in the FT-CGH analysis (online suppl. fig. 5). 


\section{Discussion}

The inv(14)(q11q32) is a known chromosomal event in lymphatic leukaemias such as $\mathrm{T}$ cell prolymphocytic leukaemia (T-PLL) [3], adult $\mathrm{T}$ cell leukaemia [4], $\mathrm{T}$ cell chronic lymphocytic leukaemia and ataxia-telangiectasia [5]. At the molecular level the inv(14)(q11q32) is very heterogeneous. It may involve a large genomic area where different genes located at 14q32: the TCL1A/ TCL1B (T cell leukaemia/lymphoma) in T cell prolymphocytic leukaemia [6], the BCL11B (B cell CLL/lymphoma 11B) gene in T-ALL [7] and the IGH locus in pre-B cell acute lymphoblastic leukaemia and T-ALL [4]. The molecular heterogeneity may reflect different biology and drug sensitivity of the leukaemic cells with the same translocation. Thus, molecular characterization of known chromosomal aberrations, including inv(14)(q11q32) may lead to better treatment of leukaemia patients. The precise molecular characterization may allow identification of sequences and therefore identification of genes involved in chromosomal aberration events and can be used for monitoring of minimal residual disease [8]. The combination of FT-CGH and LM-PCR allows not only the clarification of known breakpoints precharacterized by FISH but also unravels unknown breakpoints. Therefore, FT-CGH analysis reveals genomic imbalances (deletions, amplifications) indicating further chromosomal aberrations. These changes can be further clarified by LM-PCR and unravel so far missed alterations [9]. These combined techniques can be applied to cell lines as well as patient samples with limited percentage of malignant cells and may lead to better diagnostic and therapeutic options.

\section{Acknowledgments}

This research was supported by the Alfried Krupp von Bohlen und Halbach Stiftung 'Tumorbiologie' (K.D.), the German Josê Carreras Leukemia Foundation (P.G.) and the Polish Ministry of Science and Higher Education (G.K.P.).

\section{References}

1 Przybylski GK, Dik WA, Grabarczyk P, Wanzeck J, Chudobska P, Jankowski K, von Bergh A, van Dongen JJ, Schmidt CA, Langerak AW: The effect of a novel recombination between the homeobox gene NKX2-5 and the TRD locus in T-cell acute lymphoblastic leukemia on activation of the NKX25 gene. Haematologica 2006;91:317-321.

$\checkmark 2$ Gesk S, Martin-Subero JI, Harder L, Luhmann B, Schlegelberger B, Calasanz MJ, Grote W, Siebert R: Molecular cytogenetic detection of chromosomal breakpoints in Tcell receptor gene loci. Leukemia 2003;17: 738-745.

- 3 Leich E, Haralambieva E, Zettl A, Chott A, Rudiger T, Holler S, Muller-Hermelink HK, Ott G, Rosenwald A: Tissue micorarraybased screening for chromosomal breakpoints affecting the T-cell receptor gene loci in mature T-cell lymphomas. J Pathol 2007; 213:99-105.

4 Kamada N, Sakurai M, Miyamoto K, Sanada I, Sadamori N, Fukuhara S, Abe S, Shiraishi Y, Abe T, Kaneko Y: Chromosome abnormalities in adult T-cell leukemia/lymphoma: a Karyotype Review Committee report. Cancer Res 1992;52:1481-1493.
5 Davey MP, Bertness V, Nakahara K, Johnson JP, McBride OW, Waldmann TA, Kirsch IR: Juxtaposition of the T-cell receptor $\alpha$-chain locus (14q11) and a region (14q32) of potential importance in leukemogenesis by a $14 ; 14$ translocation in a patient with T-cell chronic lymphocytic leukaemia and ataxia-telangiectasia. Proc Natl Acad Sci USA 1988;85 9287-9291.

-6 De Schouwer PJ, Dyer MJ, Brito-Babapulle VB, Matutes E, Catovsky D, Yuille MR: Tcell prolymphocytic leukaemia: antigen receptor gene rearrangement and a novel mode of MTCP1 B1 activation. Br J Haematol 2000 110:831-838.
7 Przybylski GK, Dik WA, Wanzeck J, Grabarczyk P, Majunke S, Martin-Subero JI, Siebert R, Dolken G, Ludwig WD, Verhaaf B, van Dongen JJ, Schmidt CA, Langerak AW: Disruption of the BCL11B gene through inv(14) (q11.2q32.31) results in the expression of BCL11B-TRDC fusion transcripts and is associated with the absence of wild-type BCL11B transcripts in T-ALL. Leukemia 2005;19:201-208.

8 Boeckx N, Willemse MJ, Szczepanski T, van der Velden VH, Langerak AW, Vandekerckhove P, van Dongen JJ: Fusion gene transcripts and Ig/TCR gene rearrangements are complementary but infrequent targets for PCR-based detection of minimal residual disease in acute myeloid leukaemia. Leukemia 2002;16:368-375.

-9 Przybylski GK, Dittmann K, Grabarczyk P, Dolken G, Gesk S, Harder L, Landmann E, Siebert R, Schmidt CA: Molecular characterization of a novel chromosomal translocation $\mathrm{t}(12 ; 14)(\mathrm{q} 23 ; \mathrm{q} 11.2)$ in T-lymphoblastic lymphoma between the T-cell receptor deltadeleting elements (TRDREC and TRAJ61) and the hypothetical gene C12orf42. Eur J Haematol 2010;85:452-456. 